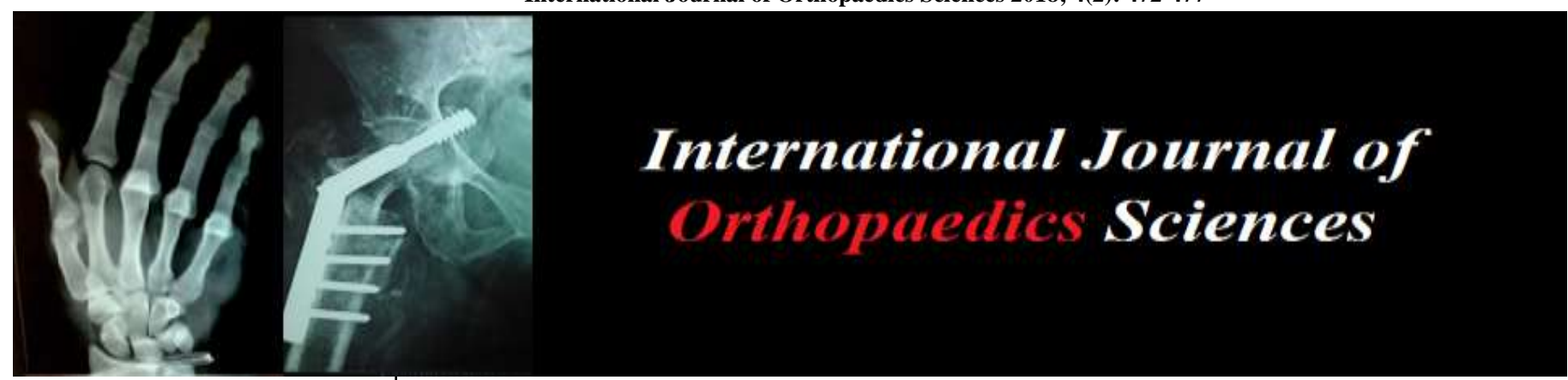

ISSN: $2395-1958$

IJOS 2018; 4(2): 472-477

(C) 2018 IJOS

www.orthopaper.com

Received: 02-02-2018

Accepted: 03-03-2018

Ahmed Alkhuzai FICMS

Faculty of Medicine Sulaimani

University/Iraq
Correspondence

Ahmed Alkhuzai FICMS

Faculty of Medicine Sulaimani

University/Iraq

\section{Comparative study of bridging Tricoticocancellous bone graft post medullary canal recanalization versus classical bone graft without opening medullary canal both procedures were used dynamic compression plate fixation in treatment of non-uniting fracture shaft humerus}

\section{Ahmed Alkhuzai FICMS}

DOI: https://doi.org/10.22271/ortho.2018.v4.i2h.71

\section{Abstract}

Background: Nonunion of a Humerus shaft fracture after conservative treatments or repeatedly failed surgical attempts bone healing a difficult therapeutic problem especially in the presence of osteoporosis, bone defect, and joint stiffness. We evaluated the treatment of nonunion of humeral shaft fracture with dynamic compression plate from June 2004 to December 2009 in Sulaimani Teaching Hospital, for healing of Nonunion fracture humerus.

Aim of study: The lack of mechanical stability due to a flail arm functionally affected that interference with personal hygiene, dressing, and daily activities. The goal of surgery is to achieve a stable rigid fixation on healed nonunion fracture humerus, plus early mobilization.

Methods: We evaluated the treatment of nonunion of humeral shaft fracture with dynamic compression plate from June 2004 to December 2009 in Sulaimani Teaching Hospital, for healing of nonunion humerus .44 patients randomly collected, classified into two groups. Group A, 22 patients were treated by recanalization opening the medullary canal with bridging Tricoticocancellous bone graft. Group B 22 patients were treated by bone graft alone without opening the medullary canal. Both groups were using compression plate Fixation in treatment of Non-uniting fracture shaft humerus.

Results: In group a, 22 patients age range 22-60 years (mean age 41years). There were 16 males and 6 females. Four patients had open fractures; (one due to explosion of a truck tire, second due to machine injury, and two dues to road traffic accidents). 8 patients had treated conservatively, 14 patients had previous surgical treatment in the form of open reduction and internal fixation using plates and screws, intramedullary nails of different types. 12 patients autogenous ICBG were used previously at least once time together with internal fixation. The mean duration of nonunion was 4 years between 2- 6 years. Group B, the mean age between 25-64 years (mean age 44.5 years). There were 18 males and 4 females' patients. Two patients had open fractures. 10 patients had treated conservatively, 12 patients had previous surgical treatment in the form of open reduction and internal fixation using plates and screws, intramedullary nails of different types. 10 patients autogenous ICBG were used previously at least once time together with internal fixation. The mean duration of nonunion was 4.5 year between $3-6$ years. We detected improvements in our study for both bone healing index results and functional index outcome. The bone results were evaluated by the union rate, angular deformity, and limb shortening. The functional outcomes were evaluated for pain, function, movement, muscle power, and patients satisfaction.

Conclusion: We confirm that recanalization opening medullary canal plus three Tricoticocancellous bone graft are superior in healing of Non-uniting fracture humerus than without recanalization nonopening medullary canal. However, we used dynamic compression plating in both techniques.

Keywords: Humeral fractures/surgery

\section{Introduction}

Fractures of the humeral shaft (diaphysis) account for approximately $3 \%$ of all fractures and represent $20 \%$ of all humeral fractures ${ }^{[1,2]}$. $80 \%$ to $90 \%$ of humeral shaft fractures are reported to be treated conservatively, with functional bracing being the most common nonoperative 
treatment option for the majority of fractures $[1,6]$. The incidence of nonunion of humeral shaft fractures is reported as $2-10 \%$ when managed conservatively, around $15 \%$ when managed by open reduction and internal fixation. Also $3 \%$ of fractures in children aged $<16$ years. Primary cause of fracture includes traffic accident, accidental falls, or violent injury ${ }^{[1,3}$, 4]. The bone can be labeled as nonunion only when the union has not occurred in the bone even after passage of sufficient time, in which the bone normally would have united. Fractures of shaft of long bone should not be considered nonunion until at least 6 months post injury. Pathophysiology of Fracture Nonunion, there are multiple factors responsible for development of nonunion, the inadequate fracture stabilization and poor blood supply are most common factors leading to nonunion ${ }^{[1,2]}$.

Operative intervention may include compression plate fixation, intramedullary nailing, or external fixation, depending on the properties of the fracture and other associated injuries ${ }^{1}$.Complications of concern perioperatively include iatrogenic comminution or radial nerve damage, nonunion, and infection ${ }^{1}$. Conservative nonoperative treatment with cast immobilization and bracing provide excellent results in over $90 \%$ of cases with union for isolated humeral shaft fractures ${ }^{[1,2]}$.

Nonunion of this fracture is a recognized complication of conservative management. In our environment where patients usually seek traditional bone setters, this remains one of the most common presentations of fractures ${ }^{[3]}$.

Varying results had been reported for different types of operative fixation with different associated morbidity relating to each method. The internal fixation methods and their common limitations include unlocked intramedullary nail with poor rotational stability, locked intramedullary nail with associated rotator cuff dysfunction and shoulder movement limitation, external fixation with pin tract infection and dynamic compression plating with wound infection and increased risk of iatrogenic or secondary radial nerve palsy ${ }^{[1-}$ 5].

Fracture humerus approximately $60 \%$ occurred in the middle third of the diaphysis with the remaining $40 \%$ in the proximal or distal third $\left(30 \%\right.$ and $10 \%$, respectively) ${ }^{[4]}$. Less than $10 \%$ of the fractures were open. The primary causes of fracture varied markedly by age and gender. High-velocity injuries occurring mostly in men and a larger peak in the seventh decade with $75 \%$ of fractures occurring in women, generally resulting from a simple fall and attributed to osteoporotic bone ${ }^{[4]}$.

Humeral shaft fractures have a high rate of union whether they are treated with open reduction and internal fixation, closed IM nailing or treated nonoperatively with a hanging arm cast or a functional brace. $90-95 \%$ of these fractures unite with good return of function ${ }^{[4-11]}$. However, up to a $13 \%-15 \%$ non-union rate has been reported following open reduction and internal fixation or closed IM nailing and up to an $8 \%$ nonunion rate has been reported for fractures treated nonoperatively ${ }^{[9]}$. When a nonunion occurs, a major therapeutic challenge is incurred, often resulting in multiple procedures. Non-union is defined here as a fracture that shows no substantial evidence of healing and exhibits pathological radiographic changes showing cessation of attempts to repair. It is a radiological as well as a clinical diagnosis ${ }^{[4-8]}$.

Causes of Nonunion of Fracture: ${ }^{[12-17]}$

Patient Related Factors;

1. Older age
2. Poor nutrition

3. Steroid therapy

4. Radiation therapy

5. Anticoagulant therapy

6. Smoking

7. High alcohol intake

8. Obesity

9. Diabetes mellitus 10 .

10. Fractures underlying burns

11. Poor patient compliance

12. Limitation of shoulder motion. Injury Related Factors

13. Open injuries

14. Transverse fractures

15. Soft tissue interposition

16. Bone loss resulting in gap

17. Compromised blood supply following injury to nutrient artery

18. Stripping injury to muscle and periosteum

19. Severe comminution

20. Infection. Treatment Related Factors

21. Inadequate immobilization

22. Malposition of fragments

23. Implant failure

24. Primary open reduction

25. Distraction of the fracture site.

Criteria Diagnosis of Non-Union of Fracture: ${ }^{[12-15]}$

1. Diagnosis is made on clinical examination and x-rays. On clinical examination, the fracture fragments would show relative mobility and there would be absence of tenderness on the fracture site.

2. Absence of tenderness differentiates nonunion from delayed union and denotes absence of any biological activity.

3. X-rays would show Absence of bone crossing the fracture site (bridging trabeculae).

4. Sclerotic fracture edges.

5. Persistent fracture lines.

6. No changes toward union on serial x-ray.

7. Presence or absence of callus is not a very reliable finding especially in cases of rigid fixation.

\section{Methodology}

We evaluated the dynamic compression plate (DCP) in the operative treatment of patients with nonunion of humeral shaft fractures. Primary cause of fracture includes traffic accident, accidental falls, or violent injury.

In prospective study of patients with Non-uniting fractures humerus shaft were selected randomly after exclusion, inclusion criteria. We evaluated the treatment of nonunion of humeral shaft fracture with dynamic compression plate from June 2004 to December 2009 in Sulaimani Teaching Hospital, also in private hospital for healing purposes. There were 44 patients randomly collected for Non-union humerus types, classified into two groups. Group A, 22 patients were treated by recanalization opening the medullary canal with bridging Tricoticocancellous bone graft. Group B 22 patients were treated by bone graft alone without opening the medullary canal. Both groups were using compression plate. Patients of nonunion humerus fractures, were previously treated by conservatively or surgically with cortical or medullary fixation. The diagnosis of a nonunion was made if the fracture failed to unite at six months as evidenced by absence of a bridging callus on X-rays and/or mobility with functional defect during movements of upper limb. The patients with active infected nonunion were excluded. 


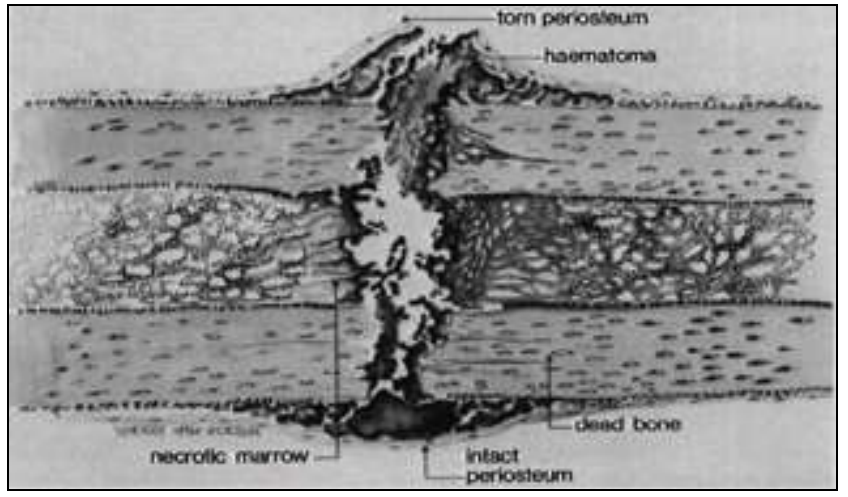

Fig 1: Intra operative Histological Nonunion humerus Methodology Operative Techniques Treatment

An anterolateral approach to the humerus was used, according to the site of the non-union. Dissection was carried out down to the non-union site.

Group A, 22 patients treated of nonunion of fracture by surgical exploration, old operative scar was used to approach the nonunion in all cases except the previous conservative treated patients. Debridement of the nonunion site entailed removal of all retained, with freshening of sclerotic edges to get a bleeding surface then opening of intramedullary cavities of proximal \& distal fragments. The Recanalization Opening the medullary canal proximally \& distally were between $6 \mathrm{~cm}$ to $16 \mathrm{~cm}$ segmental sclerotic bone closure of the medullary canal, that's causes were according to the nonunion duration times of fracture humerus. Opening by drilling bite with progressive increase the size diameter of the canal by using giant drilling bite for recanalization with opening of the medullary canal of humerus. Then grafting as bridging between proximal \& distal fracture fragment intramedullary this is the first layer, (Bone grafting to augment bone healing, autogenous ICBG was harvested from same patient bring to nonunion site), Second one cortical bridge graft, the third one is the periosteal outlay graft.

\section{As shown the Principle of Bone Graft}

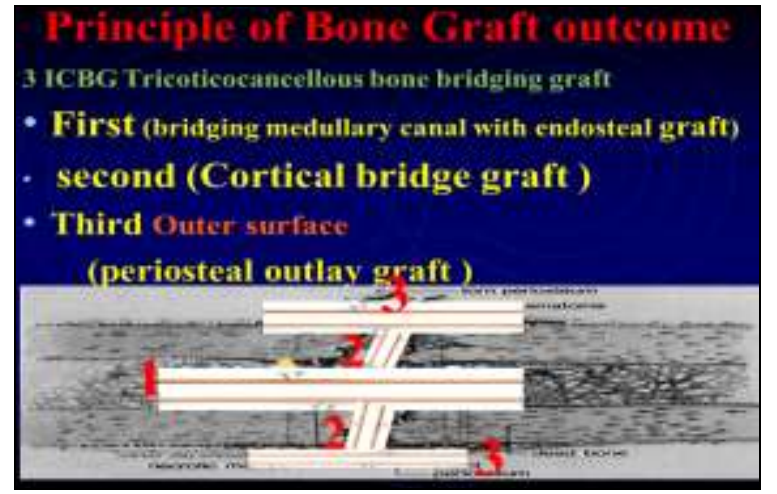

Fig 2: Intra operative Principle of Bone Graft Outcome Nonunion humerus

Group B, 22 patients were treated by bone graft alone without opening the medullary cavity \& canal, meaning just inserted the third Outer surface layer cortical bridge graft periosteal outlay graft, without opening the medullary canal and there is no bone graft fill inside the cavity.

There were both groups using dynamic compression plate for stabilization and fixation of the Humerus shaft fractures. External splintage sometimes required as functional arm brace or plastic shell or arm sling according to the fractures, then after 1-3 weeks the physiotherapy will be start.

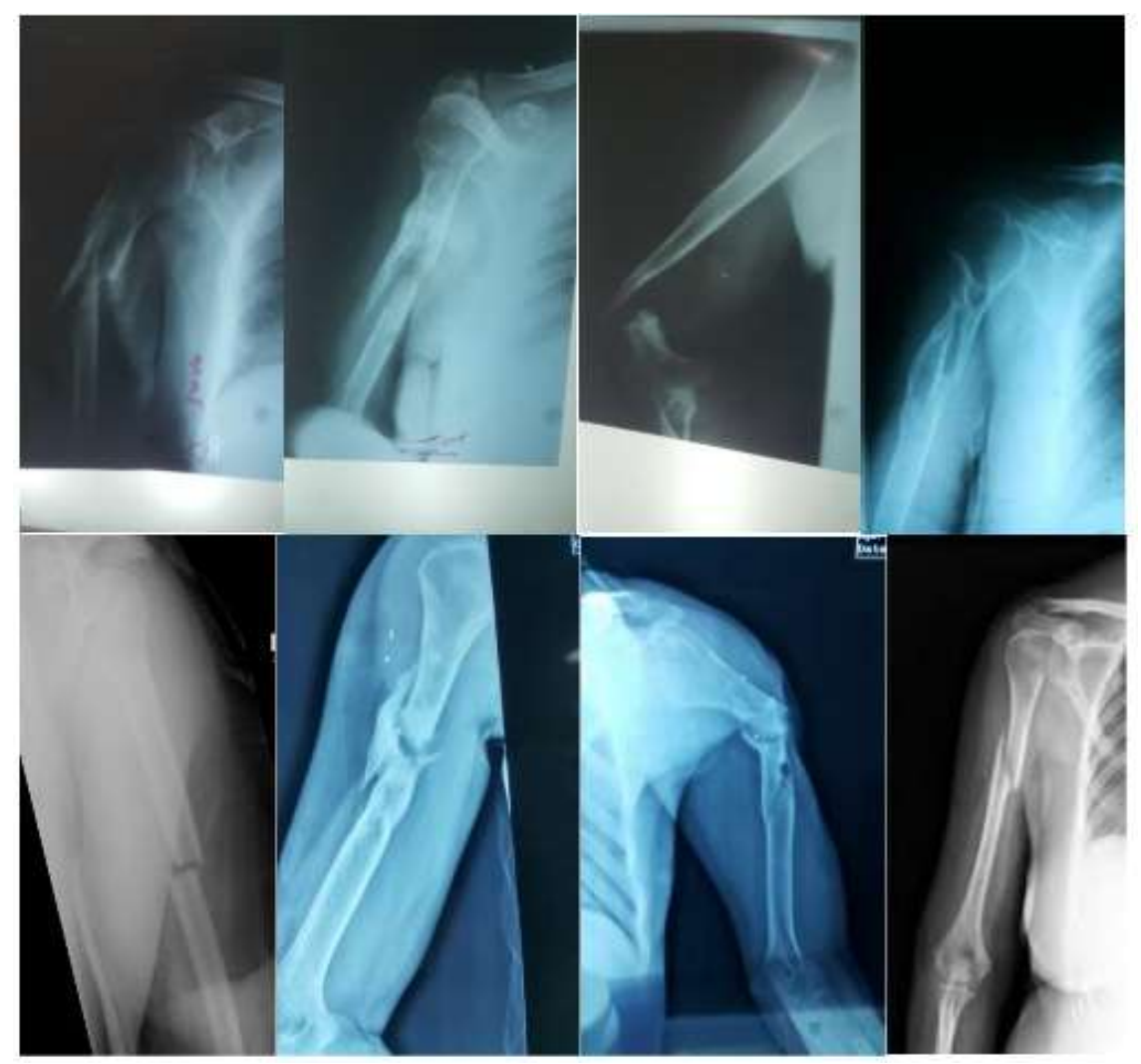

Fig 3: Nonunion fracture humerus without previous surgical intervention fixation (conservative treatment) 


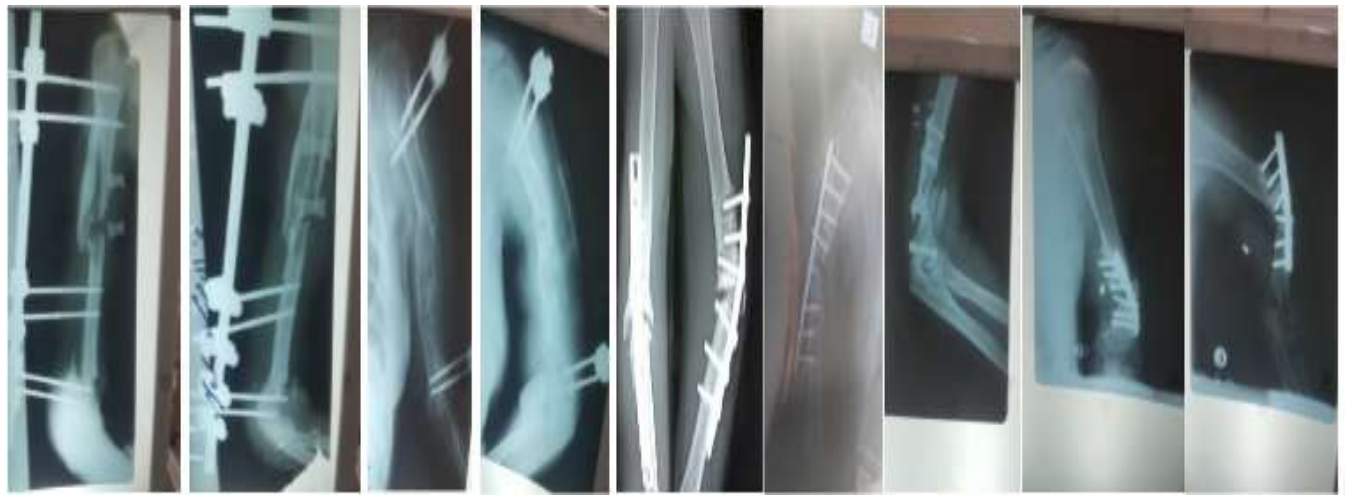

Fig 4: Nonunion fracture humerus Post-Surgical Fixation with Different Types of Fixation

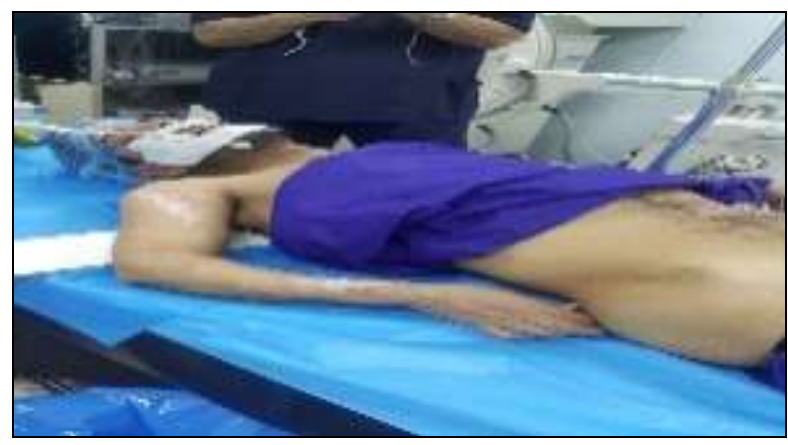

Fig 5: During surgical operation patient have previous surgery + previous bone graft

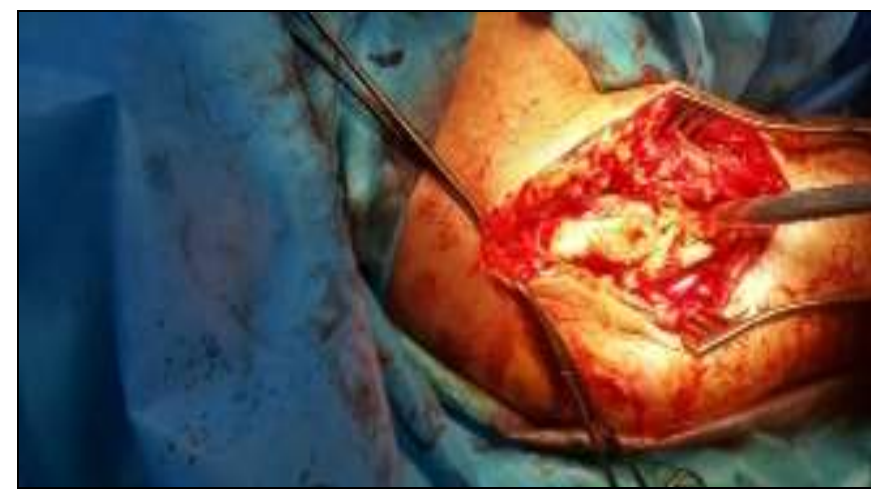

Fig 6: Intra operative nonunion humerus Segmental closure of proximal segment \& distal segment

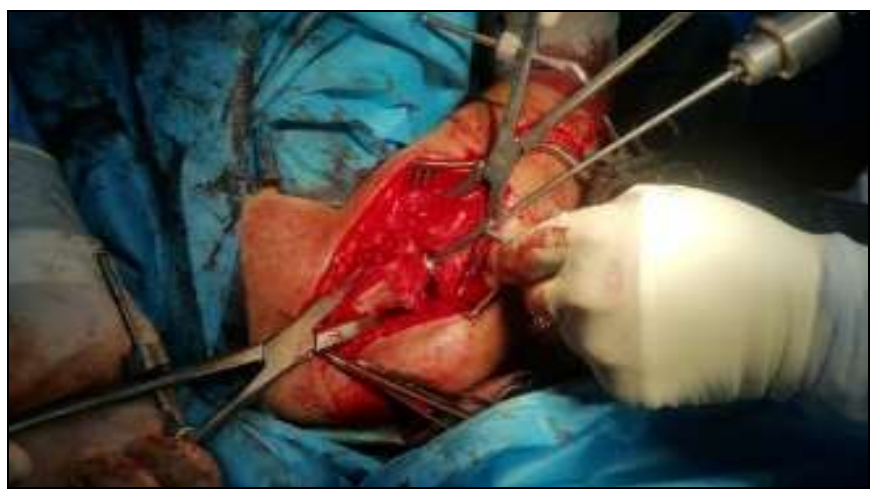

Fig 7: Intra operative nonunion humerus Segmental closure recanalization opening the proximal segment $\&$ distal segment
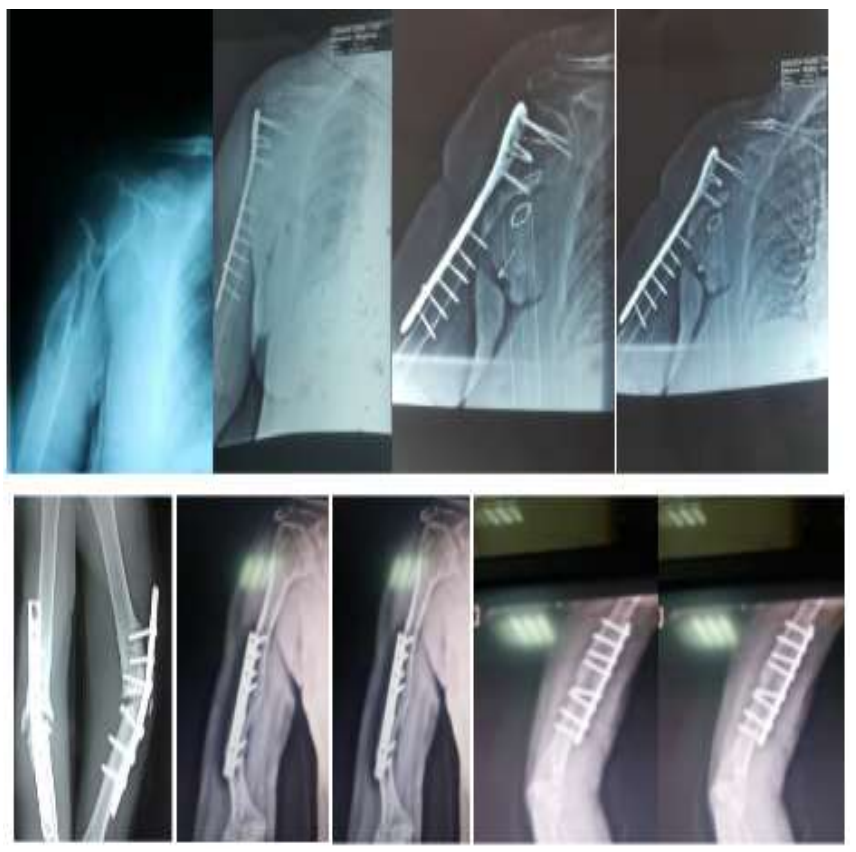

Fig 8: Preoperative/Post-operative fixation + Bone graft (from our patients) $\sim 475 \sim$ 


\section{Results}

In group A, 22 Patients age range 22-60 years (mean age 41 years). There were 16 males and 6 females. Four patients had open fractures; (one due to explosion of a truck tire, second due to machine injury, and two dues to road traffic accidents). 8 patients had treated conservatively, 14 patients had previous surgical treatment in the form of open reduction and internal fixation using plates and screws, intramedullary nails of different types. 12 patients autogenous ICBG were used previously at least once time together with internal fixation. The mean duration of nonunion was 3.5 years between 2- 5 years. Group B, the mean age between 25-64 years (mean age 44.5 years). There were 18 males and 4 female's patients. Two patients had open fractures. 10 patients had treated conservatively, 12 patients had previous surgical treatment in the form of open reduction and internal fixation using plates and screws, intramedullary nails of different types. 10 patients autogenous ICBG were used previously at least once time together with internal fixation. The mean duration of nonunion was 3 years between 2- 4 years.

All 22 patients in group A, complete healing within 3 months. No failure of healing reported in group A, were treated by recanalization of medullary canal. However, 6 patients out of 22 patients $(27.2 \%)$ in group B, reported Nonunion, that required revision later on. Angular deformity of 10 degrees in group a, 25 degrees in group B. Bone shortening of less than $1.5 \mathrm{~cm}$ was present in two cases in both groups (that because of bone loss primarily by trauma). Superficial soft tissue infection occurred in 2 patients in both groups. The functional outcome was unsatisfactory one case in group A, with six cases in group B, due to shoulder and/or elbow joint stiffness (that because delayed in treatment). There were no cases of iatrogenic nerve or vascular injury in both groups. Evaluation of results included both bone results and functional outcome. The patient was allowed to use the arm and to do active exercises of all joints. Follow-up X-rays were obtained every month until radiological bone healing and bone graft incorporation. The bone results were evaluated by the union rate, angular deformity, and limb shortening. The functional outcomes were evaluated for pain, function, movement, muscle power, and patient satisfaction.

Outcome Results:

Table 1: Bone Results: Union rate, Angular deformity, Limb shortening

\begin{tabular}{|c|c|c|}
\hline Bone Results & Group A \% & Group B \% \\
\hline Union rate & $100 \%$ & $73 \%$ \\
\hline Angular deformity & $<10 \%$ & $<25 \%$ \\
\hline Limb shortening & $1.5 \mathrm{~cm}$ & $1.5 \mathrm{~cm}$ \\
\hline
\end{tabular}

Table 2: Functional outcome: pain, function, movement, muscle power, and patient satisfaction

\begin{tabular}{|l|c|c|}
\hline \multicolumn{1}{|c|}{ Characters of Patients } & Group A & Group B \\
\hline \multicolumn{1}{|c|}{ No. of patients } & 22 & 22 \\
\hline \multicolumn{1}{|c|}{ Mean of age } & 34 years & 31 years \\
\hline \multicolumn{1}{|c|}{ Functional outcome } & 34 years & 31 years \\
\hline 1. Pain & $2(9.09 \%)$ & $4(18.18)$ \\
\hline 2. Function & $20(90.90 \%)$ & $16(72.72 \%)$ \\
\hline 3. Movement & $19(86.36 \%)$ & $15(68.18 \%)$ \\
\hline 4. Muscle power & Grade $4 / \mathrm{Good}$ & Grade $4 / \mathrm{Good}$ \\
\hline 5.patient satisfaction & $20(90.90 \%)$ & $15(68.18 \%)$ \\
\hline Total Score/Functional outcome & $90 . \%$ & $72 . \%$ \\
\hline
\end{tabular}

\section{Discussion}

The principle of fracture healing with high rate of Union, rapid healing process between proximal and distal segment through medullary recanalization techniques. Bringing osteoprogenitor cell from recipient to the donor bone graft. However, the early mobilization to prevent stiffness shoulder and elbow joint.

The reasons for non-union are multifactorial and include older age, poor nutritional status, obesity, diabetes mellitus, alcoholism, use of corticosteroids, anticoagulation, previous radiation, fractures underlying burns, and poor patient compliance. Other factors contributing to delayed or nonunion are open fractures, fractures with a transverse fracture pattern, infections, primary open reduction, soft tissue interposition, inadequate immobilization, limitation of shoulder motion and distraction of the fracture site (most often the result of a transverse or short oblique fracture treated with a hanging arm cast), support our study reason of Nonunion ${ }^{[18-20]}$.

In our study achieved high union rate, the reason for success, recanalization of medullary canal to bring the osteoprogenitor cell from donor to recipient site of nonunion, also the rigid fixation by compression plate which achieved this rate will lead to high union rate of healing similar to procedure retrospective study, with persistent humeral shaft non-unions with a comparable success rate done by Collie and co-workers at the Mayo Clinic, these patients with persistent non-unions and having had multiple previous procedures were treated with a long compression plate plus 3 Tricoticocancellous bone bridging grafts. The reasons for success, we believe, consist in debriding the tissue in the area of the non-union, plus recanalization of medullary canal, rigid internal fixation utilizing a compression plate, and firm fixation of a tricortical iliac graft to bridge the non-union site proximally and distally achieved union this explanation supported our study [21]. Humeral shaft fractures resulting in a non-union carry major therapeutic challenges, and many patients with this fracture are exposed to multiple operative procedures in efforts to achieve union. Compression plating with screws are currently the most common methods of treating non-unions, plus bone graft with humerus bone medullary recanalization same achievement in our study with high rate of bone healing [22-27]. Four authors who treated four to six nonunion each reported a $100 \%$ union rate using an interlocking IM nail compared to same results achieved in our study were used the compression plate both procedures used bone graft by recanalization of medullary canal of the humerus bone ${ }^{[28-31]}$.

Jupiter et al. achieved a $100 \%$ union rate in four patients using a vascularized fibular graft. However, with less complexity than other methods, in spite of the high rate of union achieved in our study with less complications ${ }^{[32,33]}$.

\section{Prognostic evaluation of results included both bone results and functional outcome;}

- The functional outcome was satisfactory in 21 cases (90\%) According to the scoring system in group A.

- The functional outcome was satisfactory in 16 cases (72\%) According to the scoring system in group B.

\section{Conclusion}

Although humeral shaft non-unions are not frequent, when they do occur they can be very difficult to treat. This paper presents a treatment option that has been very successful in achieving union, even in patients who have a true pseudoarthrosis. This technique offers an alternative to the 
usage of much more extensive and complicated vascularized bone grafting. Together with the specific usage of three Tricoticocancellous ICBG is a viable option to treat humeral shaft nonunion following failed Conservative or implant surgical fixation.

\section{References}

1. Burdeaux BD, Jr, York BP. Jr Treatment of difficult fractures and nonunions of the humerus and elbow with a modified Kuntscher Nail. Iowa Orthop J, 1993; 13:196203.

2. Catagni MA, Guerreschi F, Probe RA. Treatment of humeral nonunions with the Ilizarov technique. Bull Hosp Jt Dis Orthop Inst. 1991; 51(1):74-83.

3. Catteneo R, Catagni MA, Guerreschi F. Applications of the Ilizarov method in the humerus: lengthenings and nonunions. Hand Clin. 1993; 9(4):729-739.

4. Christensen S. Humeral shaft fractures: operative and conservative treatment. Acta Chir Scand. 1967; 133:455460.

5. Collie LP, Cooney WP, Kelly PJ. Nonunions of the humeral shaft. Orthop Trans. 1983; 7:517.

6. Corradi M, Petriccioli D, Panno B, Merenghi P. Seidel locked nailing for the treatment of unstable fractures and nonunion of the humerus. Chir Organi Mov. 1996; 81(2):189-195.

7. Foster RJ, Dixon GL, Bach AW, Appleyard RW, Green TM. Internal fixation of fractures and non-unions of the humeral shaft: indicators and results in a multi-center study. J Bone and Joint Surg. 1985; 67-A:857-864.

8. Healy WL, White GM, Mick CA, Brooker AF, Weiland AJ. Nonunion of the humeral shaft. Clin Orthop. 1987; 219:206-213.

9. Wu CC, Shih CH. Treatment for nonunion of the shaft of the humerus: comparison of plates and Seidel interlocking nails. Can J Surg. 1992; 35(6):661-665.

10. Zagorski JB, Latta LL, Zych GA, Finnieston AR. Diaphyseal fractures of the humerus: treatment with prefabricated braces. J Bone and Joint Surg. 1988; 70A:607-610.

11. Zuckerman JD, Koval KJ. Fractures of the shaft of the humerus. In: Rockwood CA, Green DP, Bucholz RW, Heckman JD, editors. Rockwood and Green's Fractures in Adults. Fourth Ed. Philadelphia: Lippincott. 1996; 1:1025-1053.

12. Scheerlinck T, Handelberg F. Functional outcome after intramedullary nailing of humeral shaft fractures: comparison between retrograde Marchetti-Vicenzi and unreamed AO antegrade nailing. J Trauma. 2002; 52:6071.

13. Tytherleigh-Strong G, Walls N, McQueen MM. The epidemiology of humeral shaft fractures. J Bone Joint Surg Br. 1998; 80:249-53.

14. Tytherleigh-Strong G, Walls N, McQueen MM. The epidemiology of humeral shaft fractures. J Bone Joint Surg Br. 1998; 80:249-53.

15. Wenzl ME, Porte T, Fuchs S. Delayed and non-union of the humeral diaphysis--compression plate or internal plate fixator? Injury. 2004; 35:55-60.

16. Chiu FY, Chen CM, Lin CF. Closed humeral shaft fractures: a prospective evaluation of surgical treatment. J Trauma. 1997; 43:947-51.

17. Chao TC, Chou WY, Chung JC. Humeral shaft fractures treated by dynamic compression plates, Ender nails and interlocking nails. Int Orthop. 2005; 29:88-91.
18. Tytherleigh-Strong G, Walls N, McQueen MM. The epidemiology of humeral shaft fractures. J Bone Joint Surg Br. 1998; 80(2):249-253. doi:10.1302/0301-620X.80B2.8113 [CrossRef]

19. Pugh DM, McKee MD. Advances in the management of humeral nonunion. J Am Acad Orthop Surg. 2003; 11(1):48-59.

20. Caldwell JA. Treatment of fractures of the shaft of the humerus by hanging cast. Surg Gynec and Obstet. 1940; 70:421-425.

21. McKee MD, Larsson S. Humeral shaft fractures. In: Bucholz RW, Court-Brown CM, Heckman JD, Tornetta P III, eds. Rockwood and Green's Fractures in Adults. 7th ed. Philadelphia, PA: Lippincott Williams \& Wilkins, 2010, 999-1038.

22. Ward EF, Savoie FH III, Hughes JL Jr. Fractures of the diaphyseal humerus. In: Browner BD, Jupiter JB, Levine AM, Trafton PG, eds. Skeletal Trauma: Fractures, Dislocations, Ligamentous Injuries. 2nd ed. Philadelphia, PA: WB Saunders. 1998; 2:1523-1547.

23. Matityahu A, Eglseder WA Jr. Locking flexible nails for diaphyseal humeral fractures in the multiply injured patient: a preliminary study. Tech Hand up Extrem Surg. $2011 ; 15(3): 172-176$.

24. doi:10.1097/BTH.0b013e31820ab515 [CrossRef]

25. Sarmiento A, Zagorski JB, Zych GA, Latta LL, Capps CA. Functional bracing for the treatment of fractures of the humeral diaphysis. J Bone Joint Surg Am. 2000; 82(4):478-486.

26. Stannard JP, Harris HW, McGwin G Jr, Volgas DA, Alonso JE. Intramedullary nailing of humeral shaft fractures with a locking flexible nail. J Bone Joint Surg Am. 2003; 85(11):2103-2110.

27. Hall RF, Pankovich AM. Ender nailing of acute fractures of the humerus. A study of closed fixation by intramedullary nails without reaming. J Bone Joint Surg Am. 1987; 69(4):558-567.

28. Zatti G, Teli M, Ferrario A, Cherubino P. Treatment of closed humeral shaft fractures with intramedullary elastic nails. J Trauma. 1998; 45(6):1046-1050.

Doi: 10.1097/00005373-199812000-00012 [CrossRef]

29. Stern PJ, Mattingly DA, Pomeroy DL, Zenni EJ Jr, Kreig JK. Intramedullary fixation of humeral shaft fractures. J Bone Joint Surg Am. 1984; 66(5):639-646.

30. Pugh DM, McKee MD. Advances in the management of humeral nonunion. J Am Acad Orthop Surg. 2003; 11(1):48-59.

31. Langer P, Born CT. Intramedullary fixation of humeral shaft fractures. In: Tornetta PIII, Williams GR, Ramsey ML, Hunt TR III, eds. Operative Techniques in Orthopaedic Trauma Surgery. Philadelphia, PA: Lippincott Williams \& Wilkins, 2011, 197-205.

32. Chen CM, Chiu FY, Lo WH. Treatment of acute closed humeral shaft fractures with Ender nails. Injury. 2000; 31(9):683-685.

Doi: 10.1016/S0020-1383(00)00081-4 [CrossRef]

33. Ogunlusi JD, Oginni LM, Ikem IC. Normal leg compartment pressures in adult Nigerians using the Whitesides method. Iowa Orthop J, 2005; 25:200.

34. Stannard JP, Harris HW, McGwin G Jr, Volgas DA, Alonso JE. Intramedullary nailing of humeral shaft fractures with a locking flexible nail. J Bone Joint Surg Am. 2003; 85(11):2103-2110. 